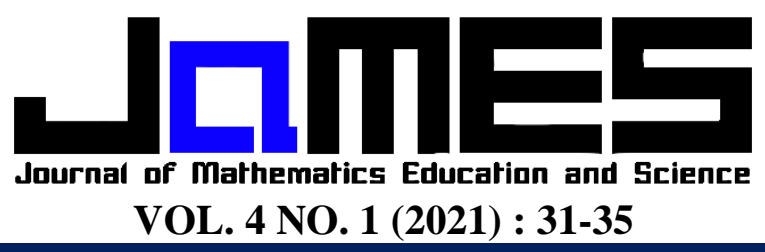

p-ISSN: 2621-1203 | https://doi.org/10.32665/james.v4i1.176

e-ISSN: 2621-1211

\title{
ANALISIS KESALAHAN SISWA DALAM MENYELESAIKAN SOAL BERDASARKAN TEORI POLYA
}

\author{
Naning Kurniawati ${ }^{1}$, Awawin Mustana Rohmah ${ }^{2}$, Suwito ${ }^{3}$ \\ Universitas Nahdlatul Ulama Sunan Giri, naningkurniawati@unugiri.ac.id ${ }^{1}$ \\ Universitas Nahdlatul Ulama Sunan Giri, awawin.emer@gmail.com² \\ Universitas Nahdlatul Ulama Sunan Giri, abcsuwito@gmail.com ${ }^{3}$ \\ Received : 20 April 2021, Revised : 28 April 2021, Accepted : 29 April 2021 \\ (C) Mathematics Education Unugiri 2021
}

\begin{abstract}
This research is motivated by the many mistakes of students in solving math problems, especially math problems in the form of stories. The student's ability to understand the story problem is determined by the student's verbal ability. Verbal ability is the ability to understand word relationships, vocabulary and quickly accept certain words, including remembering words and patterns to form them. Other causes that cause errors in solving math problems are lack of understanding of the questions, less attention to writing symbols and operations, and the absence of writing conclusions. This fact is obtained from the results of interviews with mathematics teachers and classroom observations. This study aims to identify mistakes made by students in solving problems, especially questions in the form of stories with Polya's theory. This research was conducted at one of the MTs in Dander District, Bojonegoro Regency. The research was carried out on three students who had gone through the selection. Students who are selected to be research subjects are students with low, medium, and high categories. This type of research is a qualitative descriptive study with a case study approach. The subjects of this study were several students at seventhgrade level who had passed selection according to the research objectives in 2020. The data collection method was carried out through essay tests and interview tests. The results showed that the students made six mistakes: not understanding the question, choosing the wrong strategy, not paying attention to the amount or unit, not being right in the calculation, not making the correct conclusion, and not making any conclusions.
\end{abstract}

\section{Keywords: Student's Mistake, Story Problem, Polya's Theory}

\begin{abstract}
Abstrak
Penelitian ini dilatarbelakangi oleh banyaknya kesalahan siswa dalam menyelesaikan soal matematika khususnya soal matematika dalam bentuk cerita. Kemampuan siswa dalam memahami soal cerita di tentukan oleh kemampuan verbal siswa. Kemampuan verbal merupakan kemampuan untuk memahami hubungan kata, kosakata serta menerima dengan cepat kata-kata tertentu termasuk kemampuan mengingat kata-kata dan pola membentuknya. Penyebab lain yang menyebabkan kesalahan dalam menyelesaikan soal matematika yaitu kurang memahami pertanyaan pada soal, kurang memperhatikan penulisan simbol dan operasi serta tidak adanya penulisan kesimpulan. Fakta ini diperoleh dari hasil wawancara dengan guru matematika dan pengamatan dikelas. Penelitian ini bertujuan untuk mengidentifikasi kesalahan yang dilakukan siswa dalam menyelesaikan soal khususnya soal berbentuk cerita dengan teori Polya. Penelitian ini dilaksanakan di salah satu MTs di Kecamatan Dander Kabupaten Bojonegoro. Penelitian dilaksanakan kepada 3 siswa yang telah melalui seleksi. Siswa yang terpilih untuk dijadikan subjek penelitian adalah siswa dengan kategori rendah, sedang dan tinggi. Jenis penelitian ini adalah penelitian deskriptif kualitatif dengan pendekatan studi kasus. Subjek penelitian ini adalah beberapa siswa di jenjang kelas VII yang telah melewati seleksi sesuai tujuan peneliti pada tahun 2020. Metode pengumpulan data dilaksanakan melalui tes essay dan tes wawancara. Hasil penelitian menunjukkan bahwa ada enam kesalahan yang dilakukan siswa yaitu tidak memahami pertanyaan, pemilihan strategi yang tidak tepat, tidak memperhatikan besaran atau satuan, tidak tepat dalam perhitungan, tidak tepat dalam menarik kesimpulan dan tidak adanya kesimpulan yang diberikan.
\end{abstract}

Kata Kunci: Kesalahan siswa, Soal Cerita, Teori Polya 


\section{Pendahuluan}

Lembaga sekolah merupakan salah satu wujud dari pendidikan formal yang bertujuan untuk memberikan pembelajaran yang sesuai dengan ketetapan kurikulum yang telah dibuat oleh pemerintah. Kurikulum yang dijalankan oleh lembaga sekolah diatur sedemikian rupa sehingga dapat meningkatkan kemampuan siswa dalam bidang agama, moral dan kognitif. Salah satu upaya peningkatan kognitif ditunjukkan dalam susunan bidang studi dalam kurikulum yang didalamnya memuat bidang studi matematika. Menurut Umam [1], pembelajaran matematika merupakan proses belajar mengajar yang dibangun oleh guru untuk mengembangkan kreativitas berpikir siswa yang dapat meningkatkan kemampuan berfikir serta dapat meningkatkan kemampuan mengkontruksi pengetahuan baru sebagai upaya penguasaan yang baik terhadap matematika.

Unsur-unsur yang dapat mempengaruhi keberhasilan siswa dalam belajar adalah unsur internal dan unsur eksternal. Abdul [2] mengungkapkan unsur internal meliputi minat dan bakat serta kemampuan analitis yang merupakan potensi siswa itu sendiri. Sedangkan unsur eksternal menurut Budiyono [3] yaitu keluarga, guru, kurikulum, dan metode pembelajaran serta lingkungan. Oleh karena itu pendidik harus dapat melakukan interaksi sebaik-baiknya dengan peserta didik dalam kegiatan pembelajaran agar materi yang disampaikan oleh pendidik dapat dipahami dan dimengerti oleh peserta didik, bahkan dapat menarik partisipasi siswa, sehingga pendidik tersebut dapat dikatakan berhasil dalam melaksanakan pembelajaran [4].

Kemampuan internal siswa yang rendah menyebabkan rendahnya hasil belajar siswa. Hal ini ditunjukkan adanya kesalahan siswa dalam menyelesaikan soal. sehingga hasil belajar matematika cenderung belum sesuai harapan seperti yang tertuang dalam tujuan nasional pendidikan. Berdasarkan hasil wawancara yang dilakukan kepada guru matematika di salah satu MTs Kecamatan Dander diperoleh keterangan bahwa siswa kurang mampu menyelesaiakn soal dalam bentuk cerita sehingga hasil belajar siswa belum mencapai hasil yang optimal. Menurut Afandi [5] perbedaan antara berpikir kritis siswa berkemampuan matematika tinggi, sedang dan rendah dalam menyelesaikan soal cerita. Oleh karena itu, disarankan agar guru/pendidik hendaknya memperhatikan kemampuan berfikir kritis matematika siswa dalam proses pembelajaran. kemampuan berpikir kitis siswa masih relative rendah, dan belum sistematis dalam menyelesaikan soal cerita. erdasarkan hasil tes awal, sekitar 70\% siswa kurang dapat menalar soal atau memahami maksud dari soal cerita matematika tersebut.

Peningkatan mutu pembelajaran matematika yang bertujuan untuk memperoleh prestasi belajar yang lebih baik akan tercapai jika informasi kesalahan penyelesaian soal dari para siswa dapat teridentifikasi oleh para guru. Penyebab kesalahan siswa dalam menyelesaikan soal juga perlu diperhatikan dan diidentifikasi guna mencari solusi terbaik dalam tiap pemecahan soal [6].

Salah satu soal yang efektif untuk dianalsis mengenai kesalahan yang dilakukan siswa dalam menyelesaikan masalah adalah soal cerita bentuk uraian dengan didasarkan pada tahapan Polya [7]. Soal cerita menjadi salah satu bentuk soal yang dirasakan sulit oleh siswa, karena mereka harus mampu memahami cerita terlebih dahulu sebelum menentukan strategi atau konsep yang akan dipakai. Selain itu para siswa harus mampu mengetahui satuansatuan suatu besaran yang berbeda pada soal dan harus mampu menyamakan satuan. Semua hal di atas berdasarkan dokumentasi hasil tes siswa dalam menyelesaikan soal cerita di kelas VII.

Berdasarkan hasil pengamatan peneliti, bahwa dalam kehidupan sehari-hari manusia selalu dihadapkan dengan sesuatu hal yang harus di pilih, dan dalam memilih tentunya membandingkan hal mana yang lebih menguntungkan dan relevan dengan kehidupan yang dihadapinya. Dalam belajar matematika siswa dituntut mampu membandingkan berbagai macam strategi ataupun konsep yang diketahui dan difahaminya untuk 
menyelesaikan soal-soal matematika, namun demikian terkadang masih banyak kesalahan dalam teknis perhitungan yang disebabkan kurangnya ketelitian. Dalam soal cerita matematika, bayak yang berhubungan dengan perbandingan, karena dalam soal cerita selalu menceritakan hal-hal yang berkaitan dengan kehidupan manusia sehari-hari. Seperti penelitian yang dilakukan oleh Melanie, dkk [8] yang menyatakan bahwa secara umum proses penyelesaian yang dilakukan siswa dalam menyelesaikan masalah perbandingan berbalik nilai melakukan dalam tahap-tahap berikut : tidak memahami masalah; tidak menyusun rencana penyelesaian; Tidak melaksanakan rencana penyelesaian; Melakukan perhitungan matematis; Tidak memeriksa kembali. Dari latar belakang di atas menjadi inspirasi peneliti untuk melaksanakan penelitian yang berjudul "Analisis Kesalahan Siswa dalam Menyelesaikan Soal cerita Matematika Berdasarkan Teori Polya".

\section{Metode Penelitian}

Penelitian yang dilakukan adalah jenis penelitian kualitatif deskriptif. Penelitian ini dilaksanakan di salah satu MTs Kecamatan Dander Kabupaten Bojonegoro Jawa Timur dengan kelas yang digunakan untuk mengambil data yaitu kelas VII Tahun 2020. Subjek dalam penelitian ini adalah sebanyak 3 siswa dari 39 siswa kelas VII. Penelitian menggunakan instrument soal uraian dan wawancara. Prosedur penelitian memakai beberapa tahapan, yaitu: tahap persiapan, pelaksanaan, analisis data dan tahap penyusunan laporan. Pengumpulan data ini berasal dari lembar jawaban dan hasil wawancara dengan 3 siswa dari 3 kelompok siswa berkemampuan tinggi, sedang dan rendah kelas VII.

\section{Hasil dan Pembahasan}

Secara umum, kesalahan yang dilakukan masing-masing subjek berbeda-beda yaitu subjek 1 melakukan kesalahan kurang tepat dalam menarik kesimpulan yang diakibatkan tidak meneliti kembali pertanyaan soal. Subjek 2 melakukan kesalahan konsep dan teknis perhitungan, dan subjek 3 tidak runtut dalam menerapkan konsep dan tidak tepat dalam menarik kesimpulan.

Adapun soal uraian dalam materi perbandingan adalah sebagai berikut :

a. Seorang petani mempunyai 120 ekor ayam dan persediaan pakan untuk 60 hari. Karena suatu hal, dating seorang temannya menitipkan ayam sebanyak 40 ekor, maka persediaan pakan itu akan habis dalam waktu ...hari

b. Persegi panjang $\mathrm{P}$ berukuran panjang $12 \mathrm{~cm}$ dan lebar $60 \mathrm{~mm}$, sedangkan persegi panjang $\mathrm{Q}$ berukuran panjang $0,28 \mathrm{~m}$ dan lebar $8 \mathrm{~cm}$. Perbandingan keliling kedua persegi panjang tersebut adalah....

c. Citra dan Kirana terkumpul dalam satu regu pada kegiatan perkemahan Palang Merah Remaja yang diadakan oleh SMK YPM 6 Bojonegoro pada hari sabtu dan minggu. Citra dan Kirana mewakili regunya untuk mengikuti lomba membuat es jeruk dengan bahan pokok air putih dan buah jeruk. Guna mendapatkan minuman yang segar, panitia lomba menentukan 4 macam komposisi atau campuran yang harus dipilih. Manakah campuran yang rasa jeruknya paling kuat?

Tabel 1. Tabel Soal C

\begin{tabular}{cccc}
\hline \multicolumn{2}{c}{ Komposisi A } & \multicolumn{2}{c}{ Komposisi B } \\
\hline 2 gelas air & 3 gelas & 5 gelas air & 9 gelas \\
jeruk peras & air putih & jeruk peras & air putih \\
\hline \multicolumn{2}{c}{ Komposisi C } & \multicolumn{2}{c}{ Komposisi D } \\
\hline 1 gelas air & 2 gelas & 3 gelas air & 5 gelas \\
jeruk peras & air putih & jeruk peras & air putih \\
\hline
\end{tabular}

Di bawah ini adalah jawaban dari beberapa siswa untuk soal uraian pada materi perbandingan untuk soal $\mathrm{C}$, juga hasil analisis dari masing-masing subjek.

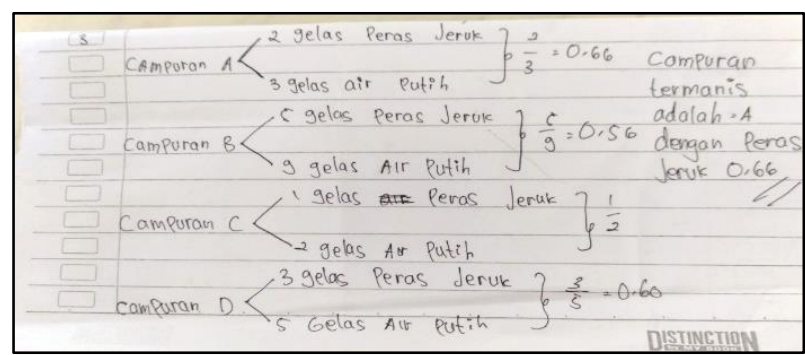

Gambar 1. Jawaban Siswa 
Berdasarkan gambar 1 peneliti menemukan jawaban yang betul namun kurang tepat. Dengan langkah-langkah yang sesuai dengan teori polya subject 1 ini memaparkan jawabannya mulai dari apa yang diketahui dalam soal, dan menggunakan strategi penyelesaian yang tepat yaitu konsep perbandingan senilai. Selain itu subjek 1 juga melaksanakan teknis perhitungan dengan baik dan benar, yaitu dengan merubah nilai perbandingan dari semua campuran perasan jeruk dengan air putih, dari pecahan sejati atau pecahan biasa menjadi nilai pecahan desimal, sehingga lebih mudah membandingkan pecahan mana yang nilainya paling besar dari campuran A,B,C, dan D. akan tetapi karena kurang teliti terhadap apa yang ditanyakan soal, maka subjek 1 menarik kesimpulan yang tidak tepat, dan memberikan alasan yang kurang jelas.

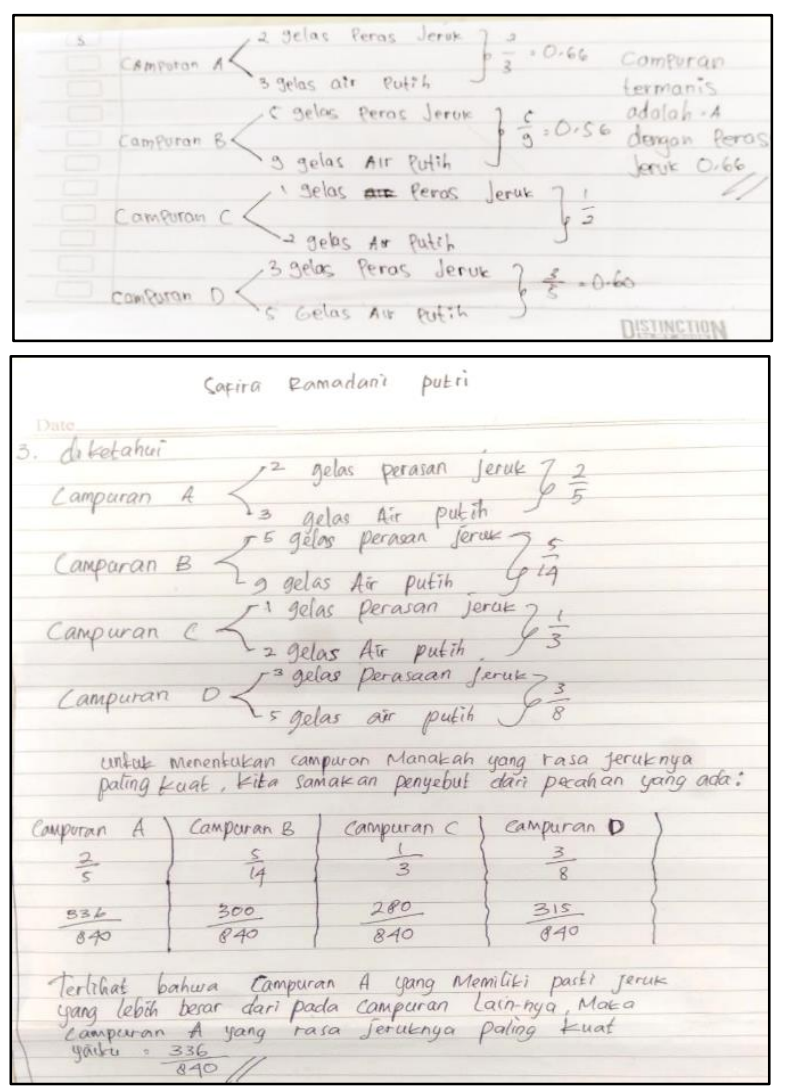

Gambar 2. Jawaban Siswa

Berdasarkan gambar 2, peneliti menemukan jawaban yang sesuai dengan langkah-langkah teori polya yaitu menuliskan sesuatu yang diketahui dan ditanyakan pada soal, namun penulisan dalam konsep perbandingan kurang sesuai yaitu menentukan penyebut dalam hal ini jumlah gelas untuk wadah air putih dirubah (diperbesar) sehingga nilai perbandingan dari masing-masing campuran menjadi kurang sederhana dan tidak senilai yaitu $\frac{2}{3}$ menjadi $\frac{2}{5}, \frac{5}{9}$ menjadi $\frac{5}{14}, \frac{1}{2}$ menjadi $\frac{1}{3}$ dan $\frac{3}{5}$ menjadi $\frac{3}{8}$. Akibat dari perubahan pecahan menjadikan teknis perhitungan yang semakin rumit dan tidak sesuai dengan nilai perbandingan yang ada pada soal, walaupun jawaban benar yaitu campuran A, yang rasa jeruknya paling kuat.

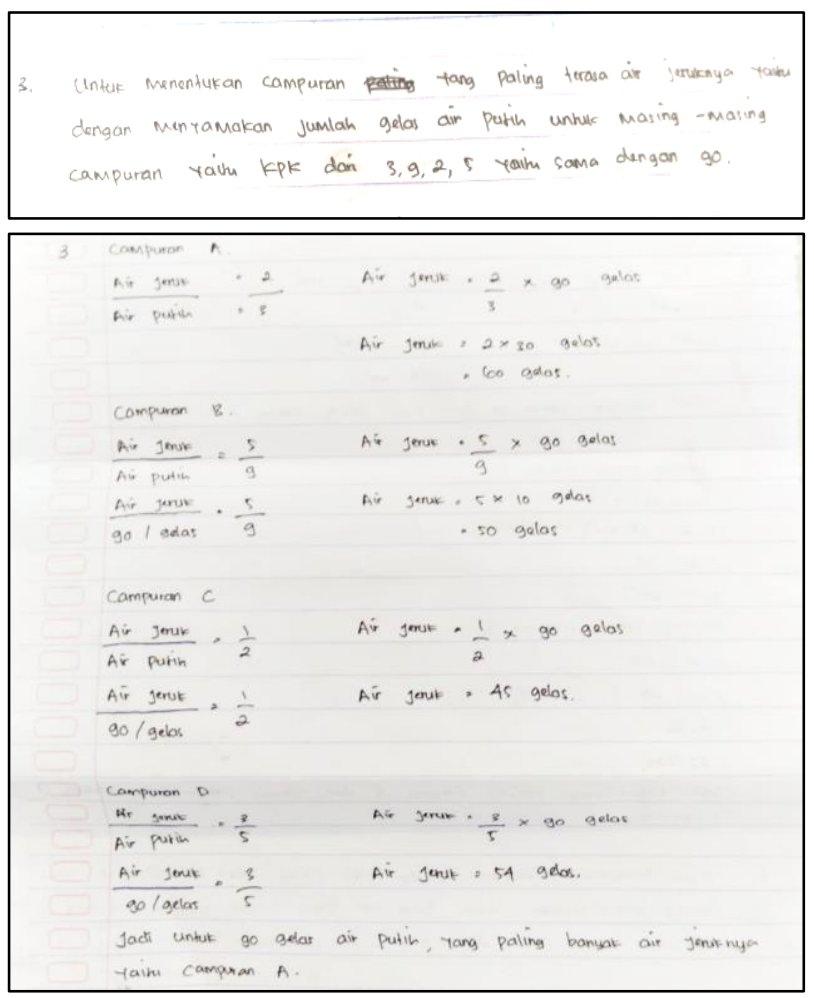

Gambar 3. Jawaban Siswa

Berdasarkan gambar 3, peneliti menemukan jawaban yang tidak sesuai dengan pertanyaan, dan langkah-langkah penyelesaiannya tidak berurutan yaitu langkah pertama yang seharusnya mengetahui apa yang diketahui dalam soal dan apa pertanyaannya, tapi subjek 3 justru menentukan konsep dengan terlebih dahulu menunjukkan rumus untuk menyamakan penyebut dari semua campuran. Untuk menyamakan penyebut dalam hal ini adalah jumlah gelas wadah air putih subjek 3 menggunakan strategi mencari kelipatan 
persekutuan terkecil (KPK) dari penyebutpenyebut pada semua campuran. Baru kemudian memaparkan apa yang ia ketahui dalam soal. Dengan mengetahui hal yang diketahui dalam soal, namun tidak mengetahui hal yang ditanyakan soal. Dalam langkah ketiga yaitu teknis pelaksanaan strategi atau teknis perhitungan juga sesuai untuk mengetahui paling banyak air perasan jeruknya pada tiaptiap campuran melalui perkalian dari masingmasing campuran dengan penyebut yang sudah disamakan dan dengan bukti adanya kesimpulan perhitungan. Pada langkah terakhir terlihat bahwa subjek 3 tidak meneliti kembali dari pertanyaan soal sehingga tidak melakukan penarikan kesimpulan yang merupakan jawaban dari pertanyaan, hal ini diketahui dari hasil wawancara.

\section{Penutup}

Peneliti menyimpulkan ada 6 kesalahan siswa, dan 6 penyebab kesalahan siswa berdasarkan analisa peneliti terhadap jawaban siswa serta hasil wawancara sebagai berikut:

Beberapa kesalahan siswa menyelesaikan soal cerita diantaranya:

a. Kesalahan siswa tidak menulis yang diketahui dalam soal

b. Kesalahan siswa dalam menentukan strategi atau rumus yang digunakan untuk menyelesaikan soal cerita

c. Siswa salah dalam menuliskan satuan pada sebuah besaran.

d. Siswa salah dalam teknis perhitungan.

e. Siswa salah dalam membuat kesimpulan.

f. Siswa salah tidak membuat kesimpulan. Diantara penyebab kesalahan siswa dalam menyelesaikan soal cerita. Yang diketahui dari hasil wawancara:

a. Siswa tidak memperhatikan dan memahami cerita.

b. Siswa tidak tepat menggunakan konsep

c. Siswa tidak memperhatikan satuan pada masing-masing besaran.

d. Siswa kurang teliti dan terburu-buru dalam perhitungan.

e. Siswa salah dalam perhitungan dan tidak meneliti kembali terhadap pertanyaan soal

f. Siswa tidak memperhatikan dan memahami pertanyaan soal.

\section{Referensi}

[1] Umam, D. Analisis Kesalahan Siswa Dalam Menyelesaikan Soal Cerita Matematika Materi Operasi Hitung Pecahan, MATHEdunesa, 3(3), (2015) 131-134.

[2] Abdul, R. Eksplorasi kesulitan dalam menyelesaikan soal cerita yang berkaitan dengan kelipatan persekutuan terkecil dan faktor persekutuan terbesar ditinjau dari perbedaan gender, Prosiding Seminar Nasional, 02, (2010) 183-190.

[3] Budiyono, Kesalahan Mengerjakan Soal Cerita dalam Pembelajaran Matematika, Pedagogia, 11(1), (2008) 1-8.

[4] Farida, N. Analisis Kesalahan Siswa SMP Kelas VII dalam Menyelesaikan Soal Cerita Matematika, 2015(2),(2015) 42-52.

[5] Afandi, A. Berpikir Kritis Siswa SMP dalam Menyelesaikan Soal Cerita Berdasarkan Kemampuan Matematika, Gammath: Jurnal Ilmiah Program Studi Pendidikan Matematika, 1(2), (2016) 1-8.

[6] Fatahillah, A. Berpikir Matematis (Matematika Untuk Semua)', Procediamath, 8(1), (2017) 40-51.

[7] Katon, K. S. and Arigiyati, T. A., Analisis Kesalahan Siswa Menurut Polya Materi Persamaan Dan Pertidaksamaan Linear Satu Variabel, Prosiding Seminar Nasional Etnomatnesia, 0(0), (2018) 576-580.

[8] Melanie, M. E., Hartoyo, A. and Ahmad, D., Deskripsi Proses Penyelesaian Soal Cerita Materi Perbandingan Pada Siswa Kelas VII SMP, Journal of Chemical Information and Modeling, 53(9), (2019) 1689-1699. 
http://journal.unugiri.ac.id/index.php/JaMES 